\title{
"El día viejo y nuevo" (Nubes, v. 1134) o las novedosas ideas del conservador Aristófanes
}

\author{
Claudia N. FERNÁNDEZ \\ Universidad Nacional de La Plata \\ claudia_fernandez@fahce.unlp.edu.ar
}

\begin{abstract}
RESUMEN: La inminente llegada del "día viejo y nuevo" desvela al endeudado Estrepsíades, el protagonista de Nubes, pues es el momento del mes en que los acreedores pueden comenzar un litigio en reclamo de la paga. La contradicción semántica inscripta en la denominación que el calendario lunar griego le asigna a este día cifra en su disputa conceptual la controvertida resolución de los sentidos de la pieza. El propósito de este artículo es ahondar en el antagonismo entre las ideas, conceptos y conductas que en la pieza representan lo viejo y lo nuevo, lo tradicional y lo innovador, en ámbitos diversos como el del conflicto generacional, y el del debate intelectual, pedagógico y poético.
\end{abstract}

$$
* * *
$$

AвSTRACт: The imminent arrival of the "old and new day" upsets Strepsiades, the debt-ridden protagonist of Clouds, because it is the time of the month when the creditors can begin to litigate to get their money back. The semantic contradiction involved in the name the Greek moon calendar assigns to this day summarizes in its conceptual dispute the controversial denouement of meanings of the comedy. The aim of this article is to explore in depth the opposition between ideas, concepts, and behaviors that express the old and the new, the traditional and the innovative, in several spheres of the play, such as the conflict between generations and the intellectual, pedagogic, and poetic debates.

Palabras Clave: Aristófanes, comedia griega, Nubes.

RECEPCIÓn: 3 de marzo de 2006.

ACEPTACIÓn: 31 de marzo de 2006. 



\title{
"El día viejo y nuevo" (Nubes, v. 1134) o las novedosas ideas del conservador Aristófanes
}

\author{
Claudia N. FERNÁNDEZ
}

Tratándose de Nubes es inevitable comenzar por lo más obvio: Nubes no es una comedia como todas. En primer lugar porque la versión que tenemos nunca fue representada. Casi con seguridad constituye un borrador intermedio, como postula Sommerstein, ${ }^{1}$ entre la versión primera, llevada a la escena ${ }^{2}$ en las Dionisias del 423 a. C., y la que finalmente nunca se representó, hacia el año 418 a. C. ${ }^{3}$ Por sus notas más peculiares Nubes es, si no la más difícil, al menos la más enigmática comedia de Aristófanes, más bien un experimento cómico que un 'híbrido dramático' como la crítica la ha catalogado. ${ }^{4}$ Mientras la comedia aristofánica por regla general tiende a las reconciliaciones y al festejo final, esta comedia realza en cambio las diferencias y los conflictos; mientras el género

\footnotetext{
${ }^{1}$ Sommerstein, $1991^{3}$.

${ }^{2}$ Obviamente usamos el término 'escena' en un sentido moderno para referir lo que en el teatro antiguo era la orchestra y la proskene.

${ }^{3}$ Numerosos estudios se ocupan por determinar cuáles son las innovaciones que la segunda versión ofrece con respecto a la primera. Un resumen del estado de la cuestión puede leerse en el prólogo de la edición de Dover, 1968, pp. lxxx ss. En lo referente a la datación de la versión que nos ha llegado, la mayoría prefiere postular el período entre el 420 y el 417 a. C., como Storey, 1993, entre otros. Contra esta suposición, Kopff, 1990, propone alguna fecha posterior al 414.

${ }^{4}$ Euben, 1996, p. 884, considera que Nubes es un híbrido de tragedia y comedia. A nuestro entender se ha sobrevalorado el perfil trágico en esta comedia, cuando en realidad se trata de paratragedia, es decir, parodia trágica en un contexto cómico. Igual observación cabe a Harriot, 1986, que vincula estrechamente el prólogo de Nubes con la tragedia euripidea.
} 
cómico favorece las movilidades que incrementan las alianzas entre los personajes, ${ }^{5}$ esta comedia promueve el movimiento contrario que convierte en antagonistas a los que antes fueron aliados. De acuerdo con esta tendencia particular de su poética, Fisher ${ }^{6}$ ha llamado la atención sobre la técnica de presentación de sus temas en pares antitéticos, disposición esta que ahonda precisamente en el contraste de los opuestos y en la imposibilidad de su conciliación. A decir verdad, el apareamiento de opuestos es un proceder común en la literatura y la filosofía griegas desde época temprana. Siguiendo esta modalidad, Nubes recorre una variada gama de oposiciones culturales, como la de la ciudad y el campo, el exterior y el interior, la aristocracia y la democracia, el conocimiento y la ignorancia, nomos y physis, lo nuevo y lo viejo, para citar los ejemplos más evidentes. ${ }^{7}$ Este último par antagónico, el que contrapone lo nuevo y lo viejo, nos parece clave y vertebrador en la organización de la narrativa de Nubes, razón que nos insta a profundizar en las tensiones ideológicas y las ambigüedades evidentes en su tratamiento. Las ideas, conceptos, conductas y hasta estilos que representan lo viejo y lo nuevo, lo anticuado y lo moderno, lo tradicional y lo novedoso, en constante pugna, inscriben su antagonismo en diversos órdenes en los que la obra negocia la oposición al tiempo que la construye. ${ }^{8}$ Y esos órdenes son:

${ }^{5} \mathrm{O}$ bien los adversarios al proyecto del héroe cómico son expulsados, o bien se integran a su proyecto como aliados y colaboradores, con lo cual se elimina cualquier peligro que empañe su triunfo. Tomemos como ejemplo Aves: Tereo, un potencial antagonista del héroe cómico, es rápidamente convertido en portavoz de Peisetero. También los embajadores que se acercan al final de la pieza terminan tomando partido por el protagonista, y hasta Zeus queda completamente desarmado sin Basíleia, y deja pues de representar una amenaza latente.

${ }^{6}$ Fisher, 1988, p. 24.

${ }^{7}$ En la misma dirección Segal, 1996, pp. 164-165: “As befits its sophistic material, the play is organized in terms of interlocking antitheses: youth and age, the new education and the old, airy theorizing and the practical necessities of paying bills, traditional morality and unscrupulous adikia".

${ }^{8}$ Euben, 1996, p. 888. 
a) el generacional: el padre anciano frente al hijo joven;

b) el intelectual: el novedoso pensamiento socrático-sofístico frente a los conocimientos, valores y creencias de la tradición;

c) el pedagógico: la vieja educación frente a la nueva, representado en el debate de los dos argumentos (logoi);

d) el poético-dramático: la renovadora y sofisticada comedia aristofánica frente a las rutinas envejecidas de sus competidores.

Veamos entonces cómo se inscriben estas contiendas en la trama cómica y, según intentaremos demostrar, cómo ningún contrincante está destinado plenamente a vencer.

\section{a) De padres y de hijos}

Es de suponer que el enfrentamiento generacional, por su potencial como resorte generador de conflictos, haya resultado un tópico estándar de la comedia aristofánica. Al menos tres de sus comedias exploran esta relación antagónica entre padres e hijos, entre viejos y jóvenes. Nos referimos a Avispas, del 422 a. C., y a la fragmentaria Comensales, del 427 a. C. En Nubes la oposición joven-viejo se manifiesta desde el mismísimo prólogo, ocasión en que el héroe cómico Estrepsíades explica a los espectadores que debe a las pasiones aristocráticas de su hijo Fidípides el desvelo por un endeudamiento para el que no tiene paga. Estrepsíades comparte con sus pares, los otros héroes de comedia, los rasgos distintivos más frecuentes: esto es, la vejez y la pertenencia al campesinado. ${ }^{9}$ En todos ellos, la vejez tiene un significado más simbólico que psicológico, pues opera como vínculo con un tiempo heroico pasado contrapuesto siempre a la decadencia del presente. El hecho de ser campesino, por su parte, también presenta no pocas implicancias axiológicas. Es innegable que a lo largo de

\footnotetext{
${ }^{9}$ Es viejo como Dicéopolis, Filocleón, Trigeo, Peisetero, el pariente de Eurípides y Crémilo, y campesino, al igual que Diceópolis, Trigeo y Crémilo.
} 
su producción Aristófanes prefirió a la gente de campo frente a sus conciudadanos. ${ }^{10}$ Hay algunos que, como Carrière, ${ }^{11}$ vieron en esta valoración una relación con los orígenes campesinos y dionisíacos del género cómico. El hombre de campo, en ese sentido, era el que entraba en contacto con las fuerzas naturales. Ambos atributos se manifiestan en la apariencia física del actor, y en tanto componentes visuales tienen entonces un fuerte poder caracterizador.

Sin embargo, Estrepsíades traiciona estas expectativas positivas del rol del rústico, porque su deseo de aprender del razonamiento injusto para no pagar las deudas que con justicia debe saldar, lo describe ajeno a la nobleza y virtudes de sus pares campesinos. Por otro lado, su condición de viejo,

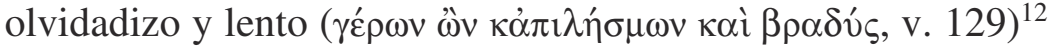
según se autopresenta, carga las tintas sobre la decrepitud del estado presente. Y eso no es todo: el viejo, en esta comedia, va a resultar un entusiasta promotor de la nueva intelectualidad sofística y de su novedoso modelo educativo. A la inversa, el joven Fidípides, permanecerá fiel a la tradición aristocrática, herencia de su renombrada familia materna ("Tengo un hijo aristócrata", le dice Estrepsíades al coro de Nubes,

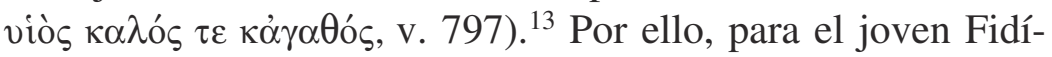

${ }^{10}$ Cuando no cae en la caricatura, como señala Borgeaud, 1993, el rústico se muestra como el depositario de antiguos valores. "El valor y el buen sentido aparecen de su parte. Incluso cuando pierde importancia económica, conserva un privilegio simbólico, el de situarse en la intersección entre lo salvaje y lo civilizado, y el de conocer por lo tanto los caminos de la urbanidad, los senderos que llevan del desorden al orden o a la inversa" (p. 335). En Aristófanes la contraposición ciudad-campo se muestra principalmente en Acarnienses y Paz.

${ }^{11}$ Carrière, 1979, p. 128.

${ }^{12}$ Citamos según la edición de Dover, 1968.

${ }^{13}$ No puede pasarnos inadvertida, tampoco a la audiencia, la defensa que de la kalokagathia ha sostenido Aristófanes a lo largo de toda su obra-Caballeros es el ejemplo paradigmático-, precisamente en razón de ser el reservorio de los ideales del pasado. Que el poco atractivo de Fidípides la represente no deja de sorprender. 
pides, Sócrates y la nueva intelectualidad de Atenas no son más que unos "charlatanes perversos, pálidos y descalzos"

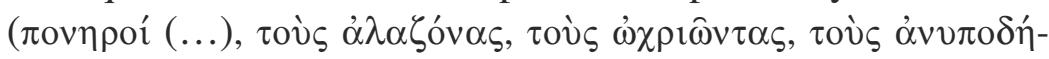

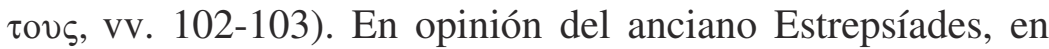

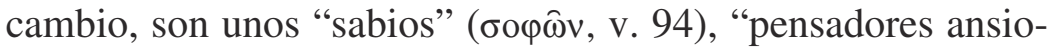
sos" ( $\mu \varepsilon \rho \mu \nu о \varphi \rho o v \tau \imath \sigma \tau \alpha i ́$, v. 101), "dueños de finezas argumentativas" ( $\lambda$ ó $\gamma \omega v(. ..) \sigma \kappa ı v \delta \alpha \lambda \alpha ́ \mu o v \varsigma$, v. 130) y "sutiles pen-

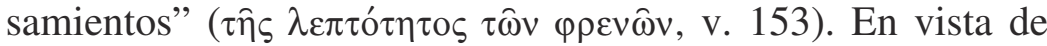
esta inclinación del personaje, podría valerle el mote de viejo 'progresista'. Las coreutas, con tono laudatorio, destacan esta disposición de su espíritu que, habiendo llegado a "lo profundo de semejante edad" (

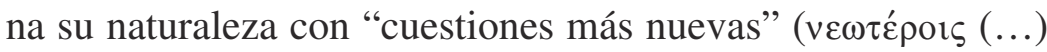
$\tau o \hat{} \pi \rho \alpha ́ \gamma \mu \alpha \sigma \iota v)(\mathrm{vv} .515-516) .{ }^{14}$ En franca oposición con el padre, Fidípides puede ser considerado más bien un joven 'conservador' o 'reaccionario'. A modo de reproche, Estrepsíades lo hace explícito a los ojos del público: "Eres un niñito

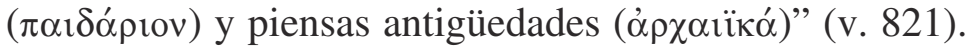

El conflicto generacional tiene un segundo momento de exposición escénica, una vez que Fidípides egresa satisfactoriamente del Pensadero socrático y se desenvuelve formalmente el segundo agón de la pieza (vv. 1321 ss.). ${ }^{15}$ Estrepsíades, diríamos hoy, organiza la fiesta de graduación para su hijo - en aquella época no podía ser otra cosa que un simposio-, festejo que prontamente se ve ensombrecido por una nueva disputa, originada esta vez en las discrepantes predilecciones poéticas de uno y otro, anciano y efebo. El hijo se niega a recitar a Simónides o a Esquilo (como se ve, poetas patrióticos, moralmente responsables, 'correctos'), simple-

\footnotetext{
${ }^{14}$ En la misma dirección, en el v. 358 el coro de las Nubes destaca la falta de correspondencia entre su edad y el deseo de aprender a discursear: "anciano entrado en años, cazador de palabras amantes de las musas".

15 Estrictamente el agón se desarrolla entre los versos 1345-1451. Nosotros incluimos en nuestras consideraciones también la escena yámbica previa, lo que comúnmente se denomina el pro-agón.
} 
mente porque los considera anticuados ( $\alpha \rho \chi \alpha i o v, ~ v . ~ 1357) .{ }^{16}$ Resignado, Estrepsíades concede que cante algo de los poetas

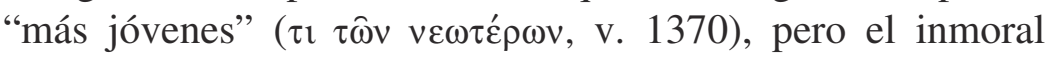
pasaje euripideo que el hijo escoge — sobre los amores incestuosos de las hijas de Eolo-, es más de lo que el padre puede soportar. ${ }^{17}$ No escapa a la audiencia, sin duda, el cambio de orientación de los personajes - el nombre parlante de Estrepsíades podría funcionar como una alerta de esta transformación-, ${ }^{18}$ claramente visible en la mención de sus nuevos gustos y opiniones. Si se considera que median razones para explicar semejante metamorfosis 'espiritual', la mudanza se torna verosímil. Fidípides llega a identificarse con los gustos y estilos de la generación más joven a instancias de un entrenamiento sofístico en el Pensadero de Sócrates. Esta educación produce inmediatamente la alienación con respecto a los lazos familiares y sociales, los de la polis y sus dioses. Y podría adjudicársele a esta 'recién adquirida' juventud la res-

16 También en Comensales (fr. 235KA) se le requiere al hijo que cante en un simposio. Cf. también fr. 225KA.

${ }^{17}$ Probablemente se trata de la tragedia Eolo de Eurípides, en cuyo prólogo se narrarían los amores incestuosos de sus hijos. Para O’ Reagan, 1992, p. 115, esta historia connota el colapso del orden familiar y social, y una hegemonía del cuerpo y de la satisfacción hedonística.

${ }^{18}$ MacDowell, 1995, p. 116, propone traducir el nombre del personaje, construido sobre la base del verbo $\sigma \tau \rho \varepsilon ́ \varphi \omega$ ("girar", "dar vueltas"), por MacTwister. En castellano sería algo así como "Vueltero" o, si se prefiere, "Tergiversero", traducción esta última que dejaría traslucir su deseo de argumentar con los medios de la retórica sofística. El uso reiterado del citado $\sigma \tau \rho \varepsilon ́ \varphi \omega$ o de términos emparentados (cf. vv. 36, 434, 776, etc.) constituye un ejemplo más de los juegos lingüísticos peculiares de la comedia de Aristófanes. Un análisis exhaustivo de los juegos y alusiones lingüísticas en toda la comedia ofrece Marzullo, 1953, haciendo hincapié en los numerosos sentidos con que se usa el verbo en el contexto de la pieza. Pucci, 1960, 16 ss., corrige algunas apreciaciones etimológicas de Marzullo. Considera en el final del nombre la presencia de $\dot{\alpha} v \delta \alpha ́ v \omega$, con lo cual el sentido del mismo podría ser " 'che si complace di trucchi' "che piace ai furfanti'” (p. 17), aunque, a decir verdad, el mismo Pucci advierte que 'Estrepsíades' (de atestiguada existencia histórica) debía sentirse como un patronímico, cuyo sentido alusivo sería "stravolgere" (p. 17). 
ponsabilidad de hacerle juzgar de anticuados los pedidos de su padre. Las prácticas distorsionadas del simposio que los reúne simboliza el fracaso de las relaciones familiares. ${ }^{19}$

Al punto que Fidípides se 'moderniza', Estrepsíades empieza a percibir los efectos negativos de la nueva retórica filosófica, lo que produce su viraje hacia la defensa de la tradición y sus ideales. De este modo la brecha generacional no pierde vigencia, pues el hijo sigue representando lo contrario a las expectativas del padre. Nada más ajeno a la superación de los conflictos que son la base de la algarabía de los finales de comedia, como el de Lisístrata, donde viejos y viejas, espartanos y atenienses, maridos y esposas, olvidan las diferencias que los mantenían enfrentados; o como el de Pluto, en que Zeus se incorpora al reinado del dios de la Riqueza. En Nubes, a medida que se acerca el desenlace, paradójicamente se regresa al punto de partida. Sumamente ilustrativo que los gritos de Estrepsíades - iov̀ iov́- con los cuales inaugura la pieza, vuelvan a oírse en el verso 1321, cuando es apaleado por su hijo. ${ }^{20}$

Para los espectadores, difícil tomar partido por una u otra de las posiciones que encarnan estas dos figuras del drama. Porque fue Estrepsíades el que obligó a su hijo a ingresar en el Pensadero, y se empieza a entrever la necesidad de que hubiera debido pagar sus deudas en vez de intentar esquivarlas como efectivamente lo ha hecho (lo acusa claramente el coro: "Eres tú culpable — aítıs - de todo por haberte volcado a asuntos perversos", v. 1454). En esa dirección será preciso pues interpretar su apaleo y el imprevisto abandono del apoyo de las Nubes como un gesto de justicia poética.

\footnotetext{
${ }^{19}$ Sobre el rol ambiguo del simposio en Nubes, ver Pütz, 2003, pp. 101 ss.

${ }^{20}$ Reckford, 1976, p. 92. Estrepsíades sale de la casa en busca de testigos para presentar en la corte un juicio contra su hijo (cf. Strauss, 1966, p. 38).
} 


\section{b) De la nueva intelectualidad}

La profusa cantidad de estudios dedicados a determinar la relación del Sócrates aristofánico con su referente histórico podría constituirse en una prueba de la extrema dificultad de acertar con una respuesta conclusiva al respecto. Por un lado están aquellos que opinan que Aristófanes no arremete contra el Sócrates real, sino contra el prototipo del pensador sofístico, al cual su figura hace alusión, y en el otro extremo los que presumen que es posible detectar una clara animosidad de Aristófanes contra el filósofo. No ahondaremos en esta cuestión. En cambio, en atención al tema que nos ocupa, haremos hincapié en el perfil innovador de la escuela socrática, aspecto especialmente destacado por la comedia y regularmente comentado por los especialistas, y en el rol también novedoso de su profesión de pensador, aspecto este menos explorado. ${ }^{21}$

De cara a Estrepsíades, Sócrates tratará de presentar una suerte de compendio de la índole revolucionaria de su doctrina. En tal sentido, lo suyo será demostrar de qué modo algunas de las convicciones o modalidades del pensamiento y del comportamiento de los atenienses resultan sin más una repetición de tradiciones infundadas, incorrectas y sin sentido. En lo que de seguro puede calificarse de muestreo, el filósofo escoge esencialmente el ámbito de la religión, la cosmología y la gramática para ilustrar y reflexionar sobre las funestas consecuencias que la situación conlleva en el orden de la vida privada y pública de los atenienses. Con ese propósito, comienza poniendo en tela de juicio al mismísimo panteón olímpico, presidido por Zeus (“'Zeus ni siquiera existe”, ov่ $\delta$ ' $\varepsilon \sigma \tau i$ Zzús, v. 367), ${ }^{22}$ para reemplazarlo por fuerzas cósmicas que

${ }^{21}$ Sobre este aspecto llama la atención Noël, 2000, en un estudio de corte léxico que releva los términos que aluden al intelecto y al intelectual en Nubes.

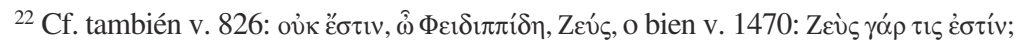


operarán de divinidades nuevas, al modo en que efectivamente el pensamiento filosófico de la época proponía hacerlo en sus revolucionarias doctrinas. Estos nuevos dioses serán el

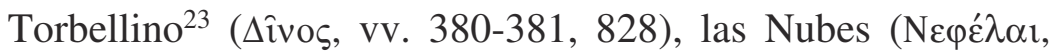

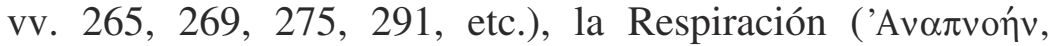
v. 627), el Caos (Xóos, vv. 424, 627), el Aire ('Aćpo, v. 627), ${ }^{24}$

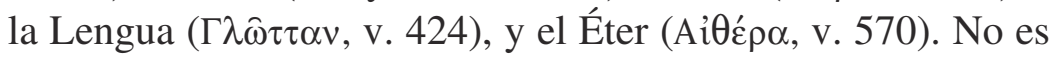
en vano recordar que la impiedad será uno de los cargos que pesará sobre el Sócrates histórico en momentos de ser condenado unos años más tarde, y también recordar la cuota de responsabilidad que el Sócrates platónico de la Apología le atribuye al propio Aristófanes al fomentar con su comedia estas falsas acusaciones. ${ }^{25}$

Con el mismo afán de renovación sobre el terreno de las convenciones heredadas deben leerse sus propuestas de transformaciones de índole lingüística. La lengua, como sabemos, es la herramienta primordial del filósofo, y Aristófanes apunta su burla a la disposición metalingüística de las charlas sofísticas, implícitamente criticadas por su naturaleza vana, improcedentes para la vida práctica. ${ }^{26}$ Efectivamente, la mirada innovadora del Sócrates aristofánico se alza también hacia el terreno del lenguaje, ámbito en el que se promueve una verdadera renovación léxica. Dos son los tipos de rectificaciones propuestas en tal sentido. En primer lugar, instituye modificaciones en el plano de la morfología, en atención a la relación

\footnotetext{
${ }^{23}$ Una noción que puede encontrarse en Anaximandro, Anaxímenes, Empédocles, Anaxágoras y los atomistas. Cf. Green, 1979, p. 18, n. 11.

24 Diógenes de Apolonia, generalmente no considerado un sofista, sostenía que el aire era el principio divino constitutivo del universo, por lo que se piensa que parte de sus doctrinas son ridiculizadas en esta pieza.

${ }^{25}$ Cf. Apología, 19c.

${ }^{26}$ Ciertamente es imposible determinar con certeza las fuentes sofísticas parodiadas, pero, en cuanto a las correcciones de tipo lingüístico, se han postulado como posibles modelos a Protágoras, para las cuestiones de género, y a Pródico para la orthoepeia. Ver al respecto el comentario al verso 659 en la edición de Sommerstein, $1991^{3}$, p. 196.
} 
arbitraria entre sexo y género gramatical. Precisamente para evitar este tipo de anormalidad, la gallina debería denominarse $\dot{\alpha} \lambda \varepsilon \kappa \tau \rho v ́ \alpha ı v \alpha$ (vv. 666, 667, 851, 852), un neologismo

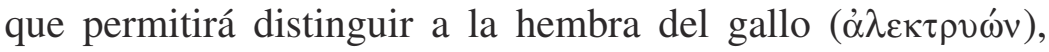
creando una posibilidad nueva en el lenguaje que hasta ese momento no contemplaba para ese caso la diversidad genérica. En segundo lugar, la percepción de que algunas desinencias nominales remiten a determinado género gramatical, induce a la corrección de $\dot{\eta} \kappa \alpha ́ \rho \delta$ ó poner en duda la masculinidad de nombres como Amynias o Melesias (vv. 685 ss.), que aparentan ser femeninos.

Pero no se trata sólo de nuevas teorías filosóficas, sino también de una nueva modalidad de transmisión de ese saber. Como didaskalos del Pensadero, Sócrates posee herramientas nuevas para que sus enseñanzas redunden en aprendizaje. Muy probablemente haya una alusión en el texto de Nubes al método de la mayéutica (vv. 135 ss.), tal como se la describe en el Teeteto platónico, cuestión ésta muy discutida por los especialistas. ${ }^{27}$ Lo cierto es que el Sócrates aristofánico se jacta de poseer, en cuestión de enseñanza, unas técnicas o tácticas innovadoras. Le pide a Estrepsíades:

Vamos, dime tu modo de ser, para que, sabiendo cuál es, te presente

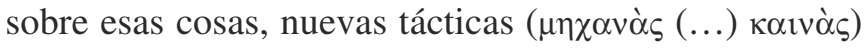

(vv. 478-480). ${ }^{28}$

De nada servirán estas tácticas, empero, para un campesino como Estrepsíades, que termina reprobado con calificativos

\footnotetext{
${ }^{27}$ Se trata del momento en que Estrepsíades golpea la puerta del Pensadero, con tanta fuerza, que el discípulo que lo recibe le reprocha haber hecho abortar un pensamiento recientemente descubierto.

${ }^{28}$ Cf. el comentario de O' Reagan, 1992, p. 65, a los citados versos: “The metaphor follows from that of the sophistic warrior but adds another dimension. Teaching Strepsiades will be like taking a city, battering down its walls. The prize inside will be Strepsiades' true and liberated self".
} 
que no hacen sino destacar la incapacidad de sus facultades, instancia que lo ha conducido irremediablemente al fracaso. Por naturaleza Estrepsíades es impermeable al conocimiento. Él es llamado "ignorante" ( $\alpha \mu \alpha \theta \dot{\varsigma} \varsigma$, vv. 135, 492), "bárbaro"

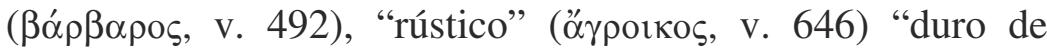

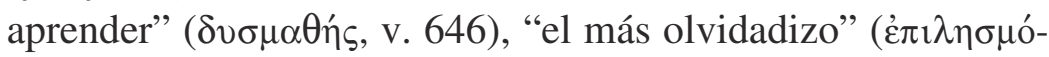

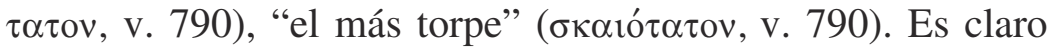
que la comedia se afana por presentar al rústico Estrepsíades en franca oposición con la figura del pensador encarnado en Sócrates. Este último es 'todo intelecto', recordemos que anda por los aires, en tanto Estrepsíades es 'todo cuerpo', o más bien 'sólo vientre'. ${ }^{29}$

Pero la instrucción impartida en el Pensadero tiene pretensiones de socavar hondo inclusive en la organización institucional ciudadana, poniendo en riesgo el funcionamiento de las cortes de la polis. La estructura judicial se desmorona ante la legitimidad de crear en cada nueva ocasión nuevos decretos y reglamentaciones que anulen los antes promulgados. Incita pues el pensamiento socrático, sacando a la luz la relatividad de la ley, a una renovación en el orden jurídico. De este modo el recién graduado Fidípides instituye, según sus necesidades, una nueva ley: la de golpear a los padres (v. 1423). La argumentación retórica es la base, sin duda, de la vida democrática ateniense; alerta esta comedia sobre la posibilidad de que ella pueda también llegar a amenazarla.

Para colmo de males, Sócrates no está solo. Forma parte del

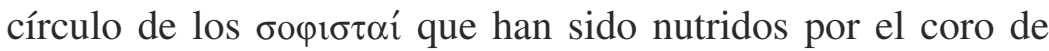
las Nubes. Por cuatro veces se menciona el término 'sofista' en Nubes, y observamos que su uso equivale al de un abarcativo, lo que la lingüística denomina hiperónimo, y acoge tanto a los interesados en las cosas celestiales (v. 360), grupo social en el que se incluye a Sócrates, pero también a otros como los

\footnotetext{
${ }^{29}$ Es típico que el héroe cómico busque ante todo satisfacer las necesidades
} del cuerpo. 


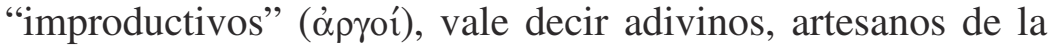
medicina, poetas y tramposos 'aéreos' (vv. 331-333). También como 'sofista' se calificará a Fidípides, una vez que sea educado por el argumento más débil (v. 1111). En forma abiertamente irónica se aplica al bruto de Estrepsíades (v. 1309). Como muy bien ha explicado Noël, el sophos define al que posee una competencia sin importar la disciplina. ${ }^{30}$ Sophistes, en cambio, construido a partir del verbo бофi agregado del sufijo - $\tau$ ऽ que designa al agente, viene a definir una actividad nueva en la Atenas del s. v, la de aquel que busca la бopía a través del razonamiento, es decir la profesión del intelectual o del pensador. ${ }^{31}$ La discriminación entre sofista y filósofo en desmedro de la valoración del primero surge recién el siglo IV y sobre todo a partir de Platón. De todos modos, quizá 'sofista' connote ya en el siglo v cierto matiz peyorativo. ${ }^{32} \mathrm{Al}$ menos en Nubes no caben dudas de que los $\sigma o \varphi ı \sigma \alpha i$ se destacan por cierto regodeo en el mero razonamiento y la naturaleza muchas veces trivial de sus lucubraciones, amén del uso arbitrario y hasta perjudicial de la retórica. Recordemos la medición del salto de la pulga, desde la ceja de Querefonte a la cabeza de Sócrates (vv. 144 ss.), o la deliberación sobre si los mosquitos cantan por la boca o por el trasero (vv. 157-158), ni qué decir de la comparación del pensamiento con los berros (v. 234), o la tendencia oscurantista de los intelectuales, ilustrada en la ceremonia de ini-

\footnotetext{
${ }^{30}$ Noël, 2000, p. 118,

31 Zimmermann, 1998, p. 104, destaca la alazoneia de la mayoría de los intelectuales de la comedia aristofánica.

${ }^{32}$ Según Dover, 1968, p. 144, podría ser el de Nubes el ejemplo más temprano del uso de sophistes en el sentido de "teacher of undesirable or superfluous accomplishments". En un comienzo sophistes podía haber funcionado como sinónimo de sophos, para designar al 'experto' en diversos ámbitos. Imperio, 1998, revisa una selección de pasajes en que se usa el término y concluye que, a partir de la segunda mitad del s. v, comienza a designar la categoría de maestro por paga, es decir, tiende a adquirir una connotación negativa.
} 
ciación a la que Sócrates somete a Estrepsíades (v. 258), o la comparación del ruido de los truenos con el meteorismo gástrico del campesino (vv. 385-387, 392-393).

Insistimos, pues, en que Sócrates no sólo introduce nuevas ideas, poniendo en tela de juicio los valores, las creencias y conocimientos heredados del pasado, sino que además lo hace desde un rol social también novedoso, el de aquel que se dedica a reflexionar. La obra se ríe y se burla de él, pero no menos de su eventual opositor, el rústico de Estrepsíades, que no puede despegar su pensamiento de la tierra, de la vida práctica y de las necesidades más primarias.

\section{c) De pedagogías}

Pero Fidípides no será instruido por Sócrates. El joven tendrá

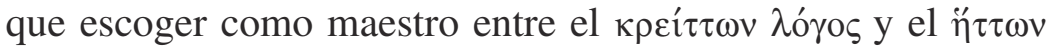
$\lambda$ ó $\gamma$ os, personificaciones alegóricas de dos modos de argumentar, que dan voz a su vez a dos tipos de educación, la tradi-

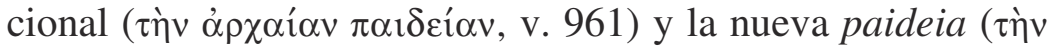

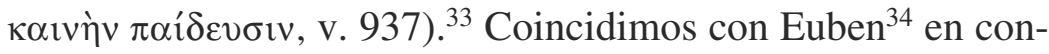
siderar que la competencia entre los logoi no es por este joven en particular, sino por todos los jóvenes de la polis. La traducción del adjetivo que les da nombre implica de hecho una interpretación de la ideología de la pieza, pues no es lo mismo denominarlos "más fuerte" y "más débil", como preferimos traducir, que "mejor" y "peor", términos que implican un juicio de valor a priori a su ejercicio retórico, menos aún, siguiendo al escoliasta, "justo" e "injusto", cuando a decir verdad nunca el argumento llamado "justo" es designado de

\footnotetext{
${ }^{33}$ Desde un primer momento Estrepsíades señala su deseo de aprender del argumento más débil, "que vence hablando cosas injustas" (v. 115). En esta afirmación puede reconocerse la expresión de Protágoras (citada por Aristóteles en Retórica, 1402a23): $\tau$ òv

${ }^{34}$ Euben, 1996.
} 
esta forma por los personajes del drama. ${ }^{35} \mathrm{El}$ grado comparativo subraya la imposibilidad de disociarlos, y cada uno se define sólo en relación con el otro, por lo que sus nombres no designan ninguna característica absoluta sino relativa a su oposición. Ambos son parte integrante del Pensadero socrático, y tampoco sería prudente entonces vincular a Sócrates

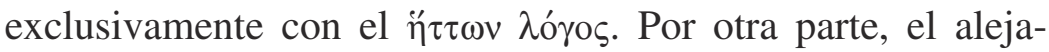
miento del filósofo de la escena cuando el debate se lleva a cabo, si bien motivado por necesidades de la representación - el actor que encarna a Sócrates tendrá que dar cuerpo al argumento más débil—, impide considerarlo cómplice de todas las aseveraciones de este último. ${ }^{36}$

La vieja Educación habla primero, lo que significa, en términos de comedia, estar condenada al fracaso. Elogia las bue-

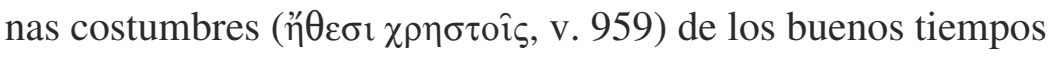
pasados ("Nuestra educación nutrió a los hombres de Mara-

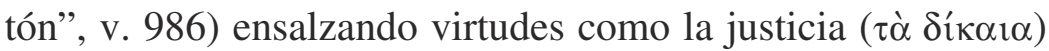

\footnotetext{
${ }^{35}$ Estrepsíades califica de adikos (vv. 116, 657, 885) al argumento más débil, pero también de hetton (vv. 113, 114, 883). Acerca de la denominación de justo e injusto observa Ambrosino, 1983, p. 30: "Il s' agit d' une interprétation banalisante, centrée sur le contenu des deux discours: on réduit ainsi leur affrontement à un combat entre le bien et le mal". Más libremente Nussbaum, 1980, propone denominarlos "Correcto" ('Right') y "Anti-correcto", para recalcar la ausencia de una propuesta constructiva del segundo, que más bien resulta una mera crítica del sistema de valores, estilo y modos de pensar que guiaba a la antigua

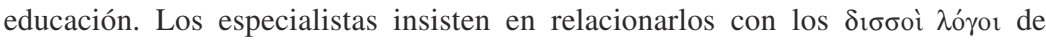
Protágoras. Newiger, 1957, p. 138, por ejemplo, sostuvo que el argumento más débil podía ser la personificación de Protágoras. Coincidimos con Pucci, 1960, p. 19, en considerarlos más bien como una reelaboración de diversas fuentes, en la que todos los elementos están fundidos en una recreación original.

${ }^{36}$ El argumento más débil defiende la fuerza de la naturaleza (v. 1075), la fuerza de los deseos; en cambio, Sócrates es presentado como alguien ascético, austero y preocupado sólo por cuestiones intelectuales, desvinculadas de los aspectos materiales de la existencia. Cf. Pucci, 1960, p. 31, n. 1: "Solo topografico appare il legame fra Socrate e i due discorsi; ma tutti i motivi che sono illustrati nell'agone, tutta la sottilissima trama di allusioni si riferisce ad altri filosofi che Socrate. (...) Gli accenni e le allusioni assai chiare sono fondamentalmente a Protagora, a Gorgia, a Prodico e ad Antifonte, mentre manca ogni accenno alla forma socratica di insegnamento".
} 


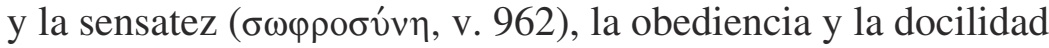
de los estudiantes que les permitirá devenir en hombres de coraje y templanza, de discernimiento moral y nada vergonzantes. Pero a cambio, la nueva educación viene a demostrar que no existe una moralidad naturalmente sancionada ("Afirmo que no existe la justicia", v. 902), y como consecuencia la deshonra puede resultar honorable ("No consideres nada vergonzoso", v. 1078). Y precisamente en este aspecto, probablemente el más controvertido, el argumento más débil será avalado por el más fuerte, reconociendo que absolutamente todos,

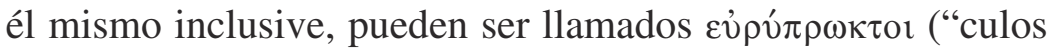
anchos"). ${ }^{37}$ Sucede que la vieja educación se limita a describir

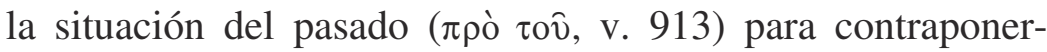
la meramente a la supuesta declinación del presente (vôv, v. 914). No sabe de oratoria, porque ésa será una prerrogativa de la nueva sofística, y se vuelve entonces vulnerable si no puede defender sus afirmaciones. Describe con nostalgia lo perdido, pero ello no es suficiente para el debate. Reproduce, en sus limitaciones, las del viejo Estrepsíades, y el argumento más débil expone esta asociación entre sus reproches: "Eres

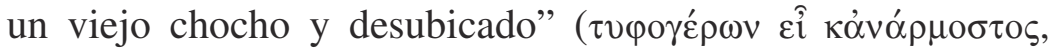
v. 908).

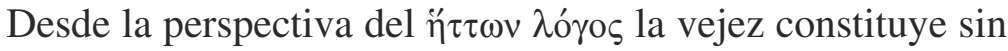
más un insulto, y el pasado, un tiempo denigrado y desprestigiado per se. Acorde con esta creencia, carga contra el argumento más fuerte tildándolo de "anticuado" ( $\alpha \rho \chi \alpha i ̂ s, ~ v . ~ 915)$, un "Cronos”, hoy diríamos 'un dinosaurio' (Koóvos, v. 929), un "caballo viejo como Cronos" (Kpóvı $\pi$ os, v. 1070), también

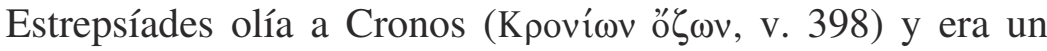
"arcaico" ( $\alpha \rho \chi \alpha i ̂ \varsigma, ~ v . ~ 1469) .{ }^{38}$ A la vez él pondrá sobre el

37 En toda la comedia de Aristófanes puede registrarse una relación entre homosexualidad pasiva y oratoria.

${ }^{38}$ Es sabido por todos que, desde la épica homérica, el viejo aventaja al joven en el consejo y la experiencia. Las obras de Aristófanes (con la excepción de Avispas y Nubes ciertamente), siguen esta tradición de pensamiento. 
tapete el carácter novedoso de sus ideas, sofisticadas e inteligentes, y destinadas a los más jóvenes: inventa nuevas ideas

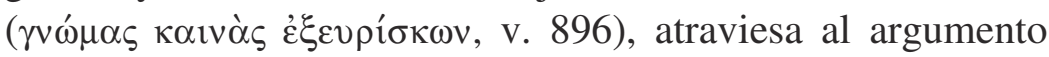

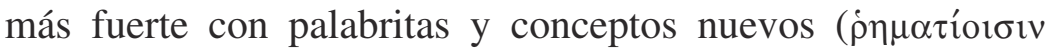

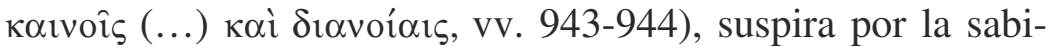

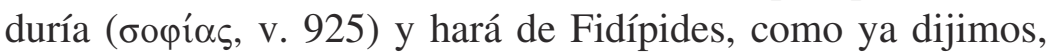

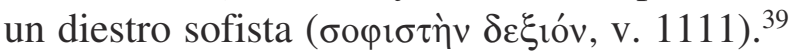

El sino de la mudanza determina el derrotero de la trama en esta comedia, y es el estado de inestabilidad permanente del coro de las Nubes que le da nombre a la pieza — de mujeres a centauros, leopardos, toros, etc., ellas pueden tomar la forma que quieran (vv. 348-352) — el más acabado emblema de la movilidad del destino que rige la lógica de todos y cada uno de los personajes. ${ }^{40}$ En ese marco no resulta sorprendente que el argumento más débil devenga el más fuerte (cf. v. 112) y persista también en ellos la pugna inacabada de lo nuevo contra lo viejo y viceversa.

\section{d) De poéticas}

Taplin destacó el carácter altamente metateatral del arte de Aristófanes, ${ }^{41}$ el más elevado antes de Pirandello, y habría que

\footnotetext{
39 "In a clash between the 'old' way —observance of tradicional virtues, social custom, and the laws - and the new — skeptical determination to enjoy whatever pleasures can be obtained with impunity - the old-fashioned violence of the hand is pitted against the modern force of the tongue", O' Reagan, 1991, p. 89.

${ }^{40}$ Por una parte, las Nubes se transforman sin cesar, a lo Proteo. En tal sentido Ambrosino, 1983, pp. 18 ss., interpreta que expresan la arbitrariedad del signo lingüístico en su devenir simbólico, pues no cambian de naturaleza, sino que reemplazan objetos por signos (toman forma de mujer, por ejemplo, cuando ven al afeminado Clístenes, v. 355). Por otra parte, mudan de pensamiento; primero aparentan estar del lado de Sócrates y ayudar a Estrepsíades, pero terminan abandonándolos. Segal, 1996, postula que su cambio hacia el final de la pieza no es más que el cumplimiento de un plan bien desarrollado y la consecuencia natural de su implícita asociación con el argumento más fuerte.

${ }^{41}$ Taplin, 1986, p. 164.
} 
añadir que Nubes es probablemente la más metateatral de entre todas sus comedias. Ella hace del autor y de su público parte del espectáculo. Muy especialmente en la parábasis el coro se erige en defensor encolerizado de la primera versión de la pieza, en opinión de su autor "la más intelectual ( $\sigma 0-$ $\varphi \omega ́ \tau \alpha \tau$ ', v. 522) de todas sus comedias". ${ }^{42}$ Ese alto grado de sofisticación se asienta, ni más ni menos, en las formas nove-

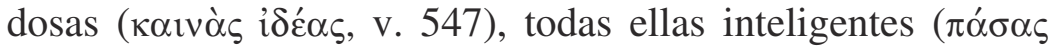
$\delta \varepsilon \xi_{\text {ló }}$, v. 548), con que el autor la ha dotado. Y esta afirmación difícilmente puede cuestionarse. Porque Nubes es novedosa en variados aspectos. Tiene un héroe cómico incompetente, condenado al fracaso, que protagoniza además la escena de comedia más violenta, como lo es el incendio del Pensadero socrático. La narrativa también tiene lo suyo: no ha pasado inadvertida la débil relación existente entre la problemática individual del héroe Estrepsíades —el endeudamiento que le han ocasionado los gustos aristocráticos de su hijo- y lo que parece ser el objetivo primordial de la vena crítica de la comedia, que es exponer el inevitable camino a la corrupción al que conduce la nueva educación, a manos de peligrosos maestros como los sofistas, ${ }^{43}$ metonímicamente representados por Sócrates. La casi nula mención a las condiciones políticas de la Atenas del momento, como la guerra del Peloponeso, no deja tampoco de sorprender. En lo formal, el carácter inusual de la párodos completa el cuadro de las innovaciones.

En efecto, el texto ahonda en el historial de la primera representación y su fracaso. Destinada a sus espectadores inte-

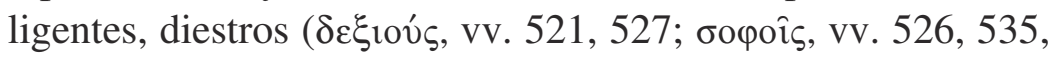
cf. también v. 575), ella misma, como acabamos de decir, representa un producto artísticamente provocador de corte

\footnotetext{
${ }^{42}$ Es difícil determinar si los primeros versos de la parábasis se refieren a la primera o a la segunda versión. La controversia sigue vigente entre la crítica.

43 Thiercy, 1986 , p. 258 , en cambio, considera que el conflicto de las generaciones y la nueva educación es el verdadero tema de la comedia y no la parodia a las enseñanzas sofísticas.
} 
intelectual. Ya hemos postulado, en un trabajo anterior, ${ }^{44}$ que la comedia ingeniosa de Aristófanes construye discursivamente una audiencia competente, e impone este modelo a sus empíricos receptores. Nubes se describe a sí misma "prudente

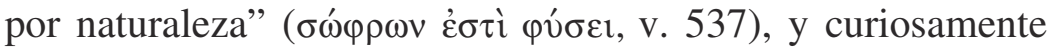

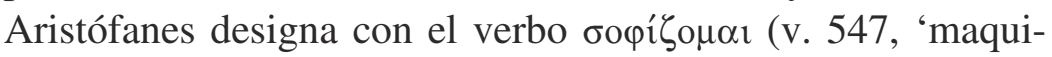
nar', 'inventar') su actividad como autor de teatro, lo que automáticamente lo convierte a él mismo en un sofista. ${ }^{45}$ Nada de viejas rutinas, como los incompetentes de sus competidores (vv. 537 ss.); a cambio, nuestro autor experimenta

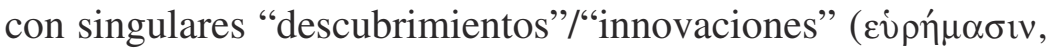
v. 561). ${ }^{46}$ No decimos nada original cuando afirmamos que el vocabulario con el cual el comediógrafo califica su obra, a sí mismo y a sus espectadores, es precisamente el mismo que en la pieza caracteriza a la escuela socrática y a sus asociados. ${ }^{47}$ Estamos pensando en términos como los que aluden al campo

\footnotetext{
${ }^{44}$ Fernández, 2000.

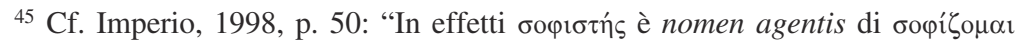
(...), che non significa propriamente 'avere la saggezza' né 'essere saggio', ma 'immaginare', 'inventare', 'escogitare', 'practicare una determinata arte' ed anche 'ingannare', magari avvalendosi di un'abilità dialettica particolarmente sviluppata (...), e dunque 'fare uso della saggezza', 'agire come un saggio' per un certo scopo: in definitiva, 'fingersi saggio' (...)”.

46 Nos referimos a los versos 537-544 de la parábasis en que se enumeran recursos cómicos vulgares como el uso del falo de cuero, danzas obscenas como el kórdax, el apaleo y las escenas con antorchas, que el autor afirma no usar, cuando efectivamente, como observa Sommerstein, $1991^{3}$, p. 188, pueden reconocerse entre los recursos de Nubes. La contradicción desaparecería si, como interpreta Hubbard, 1991, los versos en cuestión se refiriesen a la primera versión de la comedia.

${ }^{47}$ Cf. O' Reagan, 1999 , p. 69 y p. 75: “Substance, phrasing, and vocabulary alike work to link the comedian and his comedy to the picture of the sophists and their rhetoric developed in our play"; “(...) those who rise to the challenge of aristophanic comic display an intelligence also valued in the Thinkery, exercising it on verbal comic inventions which cannot be neatly separated from sophistic novelties of a similar sort". La autora intenta deshacer la aparente contradicción de este vínculo haciendo hincapié en que se trata de una construcción ficcional tanto de Aristófanes como de Sócrates.
} 
semántico de la sabiduría o inteligencia ( бopía), de la nove-

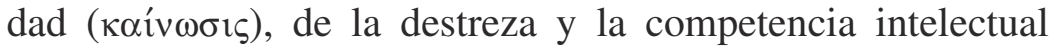
( $\delta \varepsilon \xi$ ió $\tau\rceil \varsigma)$.

Permítasenos ilustrar con algunos ejemplos. El discípulo de Sócrates habla de "invenciones" ( y los de su tipo son de la clase de los actuales "astronomosofistas" ( $\tau \hat{\omega} v v v \hat{v} \mu \varepsilon \tau \varepsilon \omega \rho о \sigma o \varphi \imath \sigma \tau \omega \hat{v}$, v. 360); con ellos, Estrep-

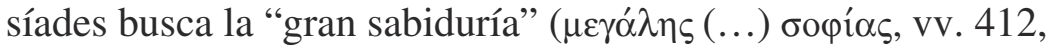
517 ) y con ellos se logra ser "inteligente" ( $\delta \varepsilon \xi$ iòv ő $\alpha \delta \rho \alpha, v$.

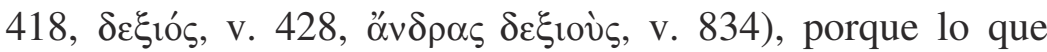
ellos enseñan es "algo ingenioso" ( $\tau \iota \delta \varepsilon \xi$ ıóv, v. 757). El Pensadero instruye en todo cuanto es sabio para los hombres ( $\sigma 0-$

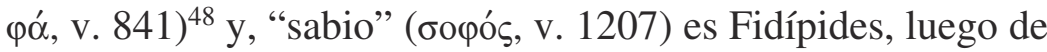
instrucción, además de "promotor y lanzador de nuevos dis-

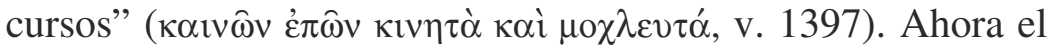
joven considera dulce "intimar con asuntos nuevos e ingenio-

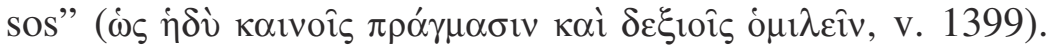

Si Nubes propone una defensa de la vieja educación al tiempo que señala los efectos corrosivos de la enseñanza de la nueva filosofía, según ha sido interpretado el sentido final de la comedia, resulta llamativo, por no decir paradójico, que el poeta redunde en calificar su comedia, su poética, a sí mismo y a la audiencia capaz de interpretarlo, con igual léxico con el que acusa a la vana y peligrosa intelectualidad representada en Sócrates. Al decir de algún comentarista, Nubes es la "más socrática" de sus piezas. ${ }^{49} \mathrm{Si}$ no, ¿cómo interpretar su combativa defensa de un tipo de comedia intelectual, sofisticada e innovadora, en la misma obra en que se acusa a los intelectuales que buscan recursos nuevos, como los que se ilustran en sus improcedentes juegos lingüísticos y sus pretensiones

\footnotetext{
${ }^{48}$ El uso de sophos aplicado al discurso y las ideas de Estrepsíades es abiertamente irónico, por ello no lo incluimos en nuestro relevamiento. También irónico el dexia del v. 852.

${ }^{49}$ Euben, 1996, p. 887.
} 
elitistas? ¿Cómo hacer para que esa crítica no recaiga sobre su propio arte, como lo ha creído efectivamente Hubbard, ${ }^{50}$ que interpreta la parábasis como una suerte de autocrítica? ¿Cómo conciliar su ideología conservadora, en temas políticos, estéticos (trágicos y musicales) e ideológicos, con su propia estética experimental?

\section{A modo de conclusión}

"Nuevo" es la palabra clave de Nubes, afirma Storey ${ }^{51}$ en un reciente prólogo a una edición de la comedia: nuevas divinidades, nuevas palabras, nuevos principios y técnicas, nueva educación y nuevas leyes se oponen a los valores, ideas y creencias del pasado. Nubes se propone ciertamente demostrar el impacto destructivo de las ideas progresistas de la nueva retórica sobre la estabilidad social y familiar. ${ }^{52}$ Sin embargo, la nostálgica defensa de la tradición, tampoco está exenta de la burla y carece además de un digno defensor que la rescate; ni el argumento más fuerte ni Estrepsíades pueden llevar adelante con éxito esta empresa. No hay vencedores en la contienda entre lo nuevo y lo viejo, y la crítica socava lo uno y lo otro, quizá no con el mismo vigor pero sí con el mismo efecto. Ni siquiera el conflicto entre el padre y el hijo, el joven y el viejo, logra resolverse satisfactoriamente. El último gesto de Fidípides es alejarse de la escena - el texto no nos informa hacia dónde (v. 1475) - sin que los personajes alcancen la reconciliación. ${ }^{53} \mathrm{Ni}$ los jóvenes ni los ancianos de la comedia encarnan los proyectos y deseos de la audiencia; el público

\footnotetext{
${ }^{50}$ Hubbard, 1986.

${ }^{51}$ Storey, 2000, p. xxxviii.

${ }^{52}$ Green, 1979, p. 16.

${ }^{53} \mathrm{Nada}$ en el texto hace suponer que reingrese al Pensadero, como propone conjeturar Nussbaum, 1980, p. 78; su instrucción sofística había finalizado.
} 
difícilmente puede identificarse con alguno de ellos. Para enturbiar más las aguas, Aristófanes defiende su arte elitista e intelectual incorporando en él las rutinas vulgares más tradicionales heredadas de la farsa popular, aquellas que critica en la obra de sus competidores. Porque Nubes es en sí misma también una curiosa amalgama de un innovador experimento dramático inscripto en la fórmula convencional del género cómico. Cuadro controvertido para un autor que cultiva para sí mismo la imagen de un artista sofisticado, innovador y malinterpretado, al tiempo que mantiene vivo el presupuesto que relaciona lo bueno con lo tradicional y lo malo con lo moderno.

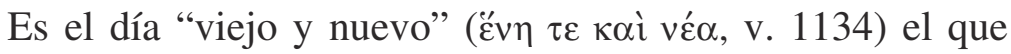
amenaza con su inminente llegada al héroe cómico de la pieza. Con esa denominación, el calendario lunar griego designa el día en que los acreedores pueden reclamar la paga ( $\mathrm{v}$. 1180).$^{54}$ Emblemático nombre para compendiar las ambigüedades y contradicciones de esta comedia. Las deudas de Estrepsíades quedan, siquiera a nivel léxico, relacionadas con el conflicto vertebrador de la comedia. Fidípides, ya convertido en sofista, pone sobre el tapete la imposibilidad de que un día sea al mismo tiempo dos días, como el nombre parecería indicarlo (v. 1184), y esa imposibilidad ilustra también sobre un debate conceptual que torna sensiblemente compleja la resolución de los sentidos de esta pieza. El espectador/lector queda definitivamente desconcertado en la tensión inacabada entre lo nuevo y lo viejo, tensión para la cual ni la fantasía cómica pudo encontrar un desenlace. No nos adherimos, por tanto, a lecturas como la de O'Reagan, ${ }^{55}$ que interpretan que la burla a ambas posturas implica impulsar a los espectadores a intentar una síntesis de tales reduccionismos. Nubes enfatiza

54 Se trata del último día del mes, fijado para depositar el monto requerido para comenzar un litigio contra el deudor.

55 O’ Reagan, 1992, p. 79. 
la destrucción, sin proponer ninguna construcción a cambio. A la actitud pesimista de su autor por la incomprensión de los primeros espectadores que no le dieron la victoria, se suma esta sensación de falta de propuestas palpables, aun cuando Estrepsíades termine incendiando, para bien de todos, el Pensadero socrático.

La situación se torna ciertamente esquiva, porque además nos enfrentamos con una 'renovada' versión de Nubes. Difícil especular sobre las razones de Aristófanes a la hora de reelaborar esta pieza, ${ }^{56}$ a no ser que pensara conceder ciertos favores al gusto poco sofisticado del grueso del público. No avala sin embargo esta suposición la parábasis de la comedia, momento en que el autor ${ }^{57}$ manifiesta su intención de no desviarse ni un ápice de su posición de no traicionar a los espectadores inteligentes, a pesar de que éstos, a juzgar por el fracaso de la primera versión, lo hubieran abandonado. Si efectivamente se trata de un borrador, ignoramos hasta qué punto se acerca a la versión que finalmente hubiera alcanzado, o si el autor estaba satisfecho con la forma que ya había obtenido. Lo cierto es que nos encontramos ante una 'nueva' versión de una comedia más 'vieja', una suerte entonces de comedia 'vieja y nueva', con todos los contrasentidos e incompatibilidades que esta denominación implica. ${ }^{58}$

${ }^{56}$ No es el único caso de reescritura en Aristófanes, sabemos de otros, como el de Paz, Thesmoforiantes, Pluto y Eolosicón.

${ }^{57}$ Se trata de un autor ficcional, vale decir, de la imagen que el autor se forja de sí mismo, y no tiene por qué confundirse sin más con el Aristófanes histórico y su pensamiento genuino. Hubbard, 1991, explica muy bien las implicancias de este hecho.

${ }^{58}$ Reckford, 1986, también llama a Nubes "old and new comedy", pero en razón de anticipar, a su criterio, lo que se da en llamar la comedia nueva, representada por Menandro. 


\section{BIBLIOGRAFÍA}

\section{Ediciones}

Aristophane, Le Commedie, ediz. crit. e trad. R. Cantarella, Milano, Istituto editoriale italiano, 1949-1964.

- Les Acharniens, Les Cavaliers, Les Nuées, texte étab. V. Coulon, trad. H. Van Daele, Paris, "Les Belles Lettres", 1980"11.

Aristophanes, Clouds, edit., introd. and comm. K. J. Dover, Oxford, Clarendon Press, 1968.

-, Clouds, edit., transl. and nts. Alan H. Sommerstein, vol. 3, Warminster, Aris \& Phillips, $1991^{3}$.

\section{Bibliografía general}

Ambrosino, D., "Nuages et sens. Autour des Nuées d'Aristophane”, Quaderni di storia, 9, 1983, pp. 3-60.

Borgeaud, Ph., "El rústico", en J.-P. Vernant, El hombre griego, Madrid, Alianza, 1993, pp. 325-338 (título original: L'uomo greco, RomaBari, 1991).

CARrière, J. C., Le carnaval et la politique. Une introduction à la Comédie grecque, suivre d'un choix de fragments, Paris, "Les Belles Lettres", 1979.

Euben, J. P., "When there are grey skies: Aristophanes Clouds and the political education of democratic citizens", The South Atlantic Quarterly, 95, 1996, pp. 881-918.

FERnÁNDEZ, C., "El público de Aristófanes: spectator in fabula", Circe, de clásicos y modernos, 5, 2000, pp. 117-136.

Fisher, R. K., "The relevance of Aristophanes: a new look at Clouds", Greece and Rome, 35, 1988, pp. 23-28.

GreEn, P., "Strepsiades, Socrates and the abuses of intellectualism", Greek, Roman and Byzantine Studies, 20, 1979, pp. 15-25.

Harriot, R. M., Aristophanes. Poet \& Dramatist, Baltimore, Johns Hopkins University Press, 1986.

Hubbard, T., "Parabatic Self-Criticism and the Two Versions of Aristophanes's Clouds”, Classical Antiquity, 5, 1986, pp. 182-197.

- The Mask of Comedy. Aristophanes and the Intertextual Parabasis, Ithaca, Cornell University Press, 1991. 
IMPERIO, O., "La figura dell'intellettuale", en AA.VV., Tessere. Frammenti della commedia greca: studi e commenti, Bari, Adriatica Editrice, 1998, pp. 43-130.

KopfF, E., "The date of Aristophanes Nubes II", American Journal of Philology, 111, 1990, pp. 318-329.

MacDowell, D. M., Aristophanes and Athens. An Introduction to the Plays, Oxford, Oxford University Press, 1995.

Marzullo, B., "Estrepsiade”, Maia, 1953, pp. 99-124.

Newiger, H.-J., Metapher und Allegorie. Studien zu Aristophanes, München, C. H. Beck, 1957.

NoËL, M.-P., "Aristophane et les intellectuels, le portrait de Socrate et des "sophistes" dans les Nuées", en AA.VV., Colloque Le théâtre Grec

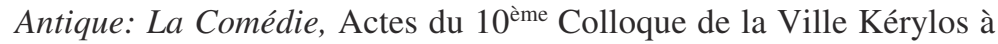
Beaulieu-sur-Mer les $1^{\text {er }} \& 2$ Octobre 1999, Paris, Académie des Inscriptions et Belles Lettres, 2000.

Nussbaum, M., "Aristophanes and Socrates on learning practical wisdom”, en J. Henderson (ed.), Aristophanes: essays in interpretation, Cambridge, Cambridge University Press, 1980, pp. 43-97.

O' Regan, D., Rhetoric, Comedy and Violence of Language in Aristophanes Clouds, New York \& Oxford, Oxford University Press, 1992.

Pucci, P., "Saggio sulle Nuvole”, Maia, 12, 1960, pp. 3-32 y 106-129.

Pütz, B., The Symposium and Komos in Aristophanes, Stuttgart, J. B. Metzler, 2003.

Reckford, K., Aristophanes' Old-and-New Comedy, Volume 1, Chapel Hill, The University of North Carolina Press, 1987.

-, "Father-beating in Aristophanes' Clouds", en S. Bertman (ed.), The Conflict of Generations in Ancient Greece and Rome, Amsterdam, B. R. Grüner, 1976, pp. 89-118.

Segal, Ch., “Aristophanes' Cloud-Chorus", en E. Segal (ed.), Oxford Readings in Aristophanes, Oxford, Oxford University Press, 1996, pp. 162-181.

Sommerstein, Alan H., cf. Aristophanes, $1991^{3}$.

Storey, C., "The dates of Aristophanes Clouds II and Eupolis' Baptai: a reply to E. C. Kopff, American Journal of Philology, 114, 1993, pp. 71-84.

-, "Introduction", en Arisophanes, Clouds, transl. with nts. Peter Meineck, Indianopolis, Hackett Publishing Company, 2000.

Strauss, L., Socrates and Aristophanes, Chicago, University of Chicago Press, 1966.

TAPlin, O., "Fifth-Century Tragedy and Comedy: A Synkrisis", Journal of Hellenic Studies, 106, 1986, pp. 163-174. 
ThIERCy, P., Aristophane: fiction et dramaturgie, Paris, "Les Belles Lettres", 1986.

Zimmerman, B., "Aristofanes e la crisi dell'educazione ateniense", en J. A. López Férez (ed.), La comedia griega y su influencia en la literatura española, Madrid, Ediciones Clásicas, 1998. 